\title{
A infância enquanto categoria estrutural ${ }^{\star}$
}

\author{
Jens Qvortrup \\ Norwegian University for Science and Technology
}

\section{Apresentação}

Nos países do hemisfério norte, um dos símbolos da consolidação de uma área de conhecimento é a publicação de um handbook em português, manual ou compêndio - cujos capítulos apresentam um breve estado da arte de seus respectivos temas. Em 2009, The Palgrave Handbook of Childhood Studies foi publicado, indicando o reconhecimento da área dos estudos da infância. Sabe-se que as crianças foram principalmente investigadas pela psicologia ou pela pedagogia e que as ciências sociais pouco produziram sobre elas, priorizando estudos sobre a família ou sobre a escola. Há pouco mais de vinte anos, entretanto, começaram a tornar-se o foco dos estudos sociais da infância, que a tomaram como um fenômeno social. Nesse sentido, foi definido um campo que investiga as crianças como agentes sociais, produtoras de culturas, e a infância como categoria na estrutura social, o que ampliou de modo significativo a produção de conhecimento sobre as relações sociais estabelecidas entre as próprias crianças (seus pares) e com os adultos (relações intra e intergeracionais), sobre suas competências como protagonistas de suas vidas, como agentes sociais cuja ação modifica/transforma os mundos sociais nos quais estão inseridas. 0 texto do Prof. Jens Qvortrup, responsável pela constituição do primeiro grupo de pesquisa no campo da sociologia da infância (RC53) na Associação Internacional de Sociologia (ISA), e um dos organizadores do Handbook, trata da infância como estrutura social. Publicado como primeiro capítulo do The Palgrave Handbook of Childhood Studies, o trabalho apresenta a infância como segmento na estrutura social e as aplicações de uma perspectiva estrutural, ou seja, inserido nos fundamentos teóricos dos estudos da infância, o capítulo define uma abordagem que difere tanto de pesquisas sobre socialização quanto de estudos sobre desenvolvimento infantil, oferecendo elementos para a realização de pesquisas que tenham como objeto a infância como categoria social, portanto diversa e complementar às outras categorias. A leitura do texto remete a outros te-

* Tradução do texto "Jens Qvortrup, William A. Corsaro and MichaelSebastian Honig 'The Palgrave handbook of childhood studies'. Cap. 1, England: Macmillan Publischers Limited, 2009 p. 21-23". Feita por Giuliana Rodrigues com revisão técnica de Maria Letícia B. P. Nascimento. mas, tratados por diferentes autores nos demais capitulos, o que faz os pesquisadores brasileiros almejarem a tradução integral do livro.

\section{Palavras-chave}

Infância - Estrutura social - Sociologia da infância. 


\title{
Childhood as a structural form
}

Jens Qvortrup

Norwegian University for Science and Technology

\begin{abstract}
In northern countries, a symbol of the consolidation of a knowledge area is the publication of a handbook - in Portuguese, manual or compendium - whose chapters give a state-of-theart overview of their respective subjects. In 2009, The Palgrave Handbook of Childhood Studies was published as recognition of the area of childhood studies. It is known that children were mainly investigated by psychology or by pedagogy and that social sciences have produced little about them, giving priority to studies on the family or the school. Just over twenty years, however, children become the focus of social studies of childhood, as social phenomenon. In this sense, there is the field that investigates children as social agents, producing culture, and childhood as category in the social structure, which increased significantly the production of knowledge about the social relations established between the children themselves (their peers) and with adults (intra and intergenerational relations) on their skills as actors in their lives, as social agents whose actions modify / transform the social worlds in which they are inserted.

The text of Professor Jens Qvortrup, responsible for the foundation of the first research group in sociology of childhood (RC53) at the International Sociological Association (ISA), and one of the organizers of the Handbook, focuses childhood as a social structure. Published as first chapter of The Palgrave Handbook of Childhood Studies, the study shows childhood as a segment in a social structure and the applications of a structural perspective, i.e. inserted in the theoretical studies of childhood, the chapter outlines an approach that differs from both research on socialization and studies on child development, providing evidence for the conduct of research that have as their object childhood as a social category, so diverse and complementary to other categories. The reading of the text directs to other important themes, presented by different authors in the other chapters of the Handbook, which makes Brazilian researchers expect the full translation of the book.
\end{abstract}

\section{Keywords}

Childhood - Social structure - Sociology of childhood. 


\section{O cenário}

Os conceitos complementares "estrutura" e "agência" têm sido úteis à Filosofia e à Sociologia desde tempos imemoráveis - ainda que porventura sob outras denominações. É comum propor, por exemplo, que a mudança social resulte tanto da interação entre as condições estruturais quanto da intervenção humana consciente e deliberada, A estreita relação entre os dois conceitos determina a direção e a velocidade das mudanças sociais, sendo de interesse contínuo, portanto, a busca pela relação entre as forças estruturais e a ação humana com o propósito de atingir um equilíbrio. A despeito disso, esse é um assunto que promove debates, em que quase inevitavelmente são geradas frentes de batalha nas quais tanto "deterministas" quanto "voluntaristas" colocam-se por trás de uma fortaleza - essa é, pelo menos, a frequente percepção e acusação mútua dos adversários.

Pareceres contra essa e outras dicotomias sociológicas tradicionais têm sido frequentemente apresentados, além de muitos duvidarem de sua utilidade. Apesar disso, no final do século XX, a introdução e a ampla aplicação dos termos estrutura e agência, e sua inter-relação, era algo novo, tido como significativo para os estudos sobre a infância. Não se quer dizer, entretanto, que antes as crianças não tenham sido consideradas indivíduos ativos, ou tivessem sido tratadas como se pertencessem ao mesmo grupo que os adultos, mas sugere que, com os estudos sociais da infância, as pesquisas sociológica e antropológica pela primeira vez - quase de maneira programática - começam a ser sérias sobre estrutura e agência no que diz respeito à infância e à criança.

De fato, de acordo com a socióloga canadense Anne-Marie Ambert, que há duas décadas documentou o que chamava de "quase inexistência" de estudos sobre a infância nas principais correntes da Sociologia, isso era uma novidade. Seu estudo incluiu sociólogos clássicos como Comte, Marx, Pareto, Weber, Durkeim, Simmel, Mead, Parsons, e Merton, os quais evitavam, propositadamente ou não, a in- fância enquanto assunto de discussão; a autora descobriu que a situação não estava melhor nos livros escolares de Sociologia moderna nem nos periódicos da área (Ambert, 1986). A questão sobre a possibilidade dessa marginalização era levantada como sintomática da posição da infância na sociedade.

Era uma quase inexistência de estudos, como escreve Ambert, no entanto, podemos encontrar publicações daquela época que eram relacionadas às crianças - até mesmo publicações que levam o título "Sociologia da Infância" ou coisa semelhante. E, mesmo assim, o conteúdo desses trabalhos geralmente não representava um novo pensamento, mas permanecia fiel à socialização, "assunto principal da Sociologia da Infância”, como afirmou um dos autores (Fürstenau, 1973, p. 11). Isso também era verdade para alguns sociólogos mais conhecidos do século XX, como Talcott Parsons e Kingsley David renomados representantes da orientação estrutural-funcionalista. Para alguém interessado em infância e estrutura social, o título de um artigo de Davis, de 1940, causou alguma expectativa: "A criança na estrutura social". No entanto, um novo direcionamento não era questionado em termos de reconhecimento da infância enquanto categoria na estrutura social; Davis (1940) talvez tenha impetrado o golpe mais definitivo contra tal aspiração quando declarou que:

As funções mais importantes de um indivíduo para a sociedade são desempenhadas quando ele é um adulto pleno, não quando é imaturo. Por essa razão, o comportamento da sociedade para com a criança é sobretudo preparatório, e a sua avaliação é essencialmente antecipatória (como uma poupança bancária). Qualquer doutrina que compreenda as necessidades da criança como sendo de suma importância e as da sociedade organizada como de importância secundária é "anomalia sociológica”. (p. 217)

Mesmo que alguns sociólogos tenham feito abordagens teóricas sobre as crianças, alguém 
ainda pode sugerir que a observação de Ambert é confirmada pelo modo como eles abordaram a questão; ou seja, por meio de um olhar avançado, antecipatório, ou, nas palavras de David, por uma perspectiva "preparatória”. Apesar de registros feitos de maneira impecável por alguns sociólogos eminentes para avaliar com precisão o significado da estrutura social, todos eles, quando se trata de crianças, falham por não pensar em termos de estrutura, ainda mais em crianças enquanto uma categoria social ou um coletivo - salvo talvez o fato de que todas elas estão caminhando em direção à idade adulta. As crianças têm, portanto, algo significativo em comum, ou seja, sua saída da infância. A antecipação da idade adulta e a trajetória em direção a ela não apenas descrevem às crianças as atitudes dos adultos, mas, também, as transformam em proporções agigantadas para as crianças; as características determinam de forma significativa as expectativas dos adultos diante das crianças e o comportamento daqueles em relação a estas, bem como as expectativas das crianças em relação ao seu próprio desempenho e realizações. A "invasão implacável da torrente de bebês recém-nascidos”, como expôs Parsons (1964), é “certamente, uma característica decisiva da situação de qualquer sociedade” (p. 208) ${ }^{1}$, porque se trata de um desafio para qualquer sociedade socializar as crianças às suas normas, com o objetivo de integrá-las completamente ao meio - isto é, à sociedade adulta. As explicações de Parsons sugerem que isso nem sempre aconteceu sem tensão e resistência ${ }^{2}$. Ele falhou, no entanto, em fornecer uma abordagem sociológica satisfatória, porque, do ponto de vista dele e da maioria dos outros sociólogos, as crianças não possuíam agência, e a noção de infância enquanto categoria na estrutura social estava fora de cogitação.

A pergunta reside em saber se é relevante e plausível entender as crianças como atores competentes na sociedade e perceber a infância em termos estruturais. 0 segundo aspecto é o tema deste artigo.

Embora para os pesquisadores bem versados em estudos sociais da infância essa discussão possa parecer ultrapassada, ela tem um significado histórico. A pergunta a ser respondida, há um quarto de século, era como um adulto poderia interagir com as crianças de uma forma mais positiva, ao invés de simplesmente tolerá-las por aquilo que elas viriam a se tornar ${ }^{3}$. Como poderíamos fazer justiça à infância e às crianças enquanto elas ainda eram crianças e membros da infância? Não se tratava, nesse caso, de um plano revolucionário, mas apenas se esboçava uma modesta reivindicação analítica com o intuito de prover as crianças e a infância de "autonomia conceitual", conforme formulou Barrie Thorne (1987, p. 103) em um importante artigo. Essa reivindicação se refletiu em uma demanda pela concessão de visibilidade à infância e de voz às crianças, ou, para usar outra frase típica, lidar com a infância e as crianças por elas mesmas, ou seja, sem ter de necessariamente fazer referência ao seu futuro, quando se tornarem adultas.

\section{A infância enquanto categoria na estrutura social}

Em linguagem coloquial e no discurso científico, a infância é comumente caracterizada como um período. 0 período que temos em mente é relativo ao indivíduo e pode ter várias durações; de qualquer forma deve ser o período de tempo que demarca o começo e o fim da infância individual de uma pessoa. É difícil deixar de pensar nesses termos, pois cada um de nós está ansioso para prever o que acontecerá conosco durante a nossa própria fase adulta e

1. Parsons pode ter emprestado a expressão de Ortega y Gasset, que falou sobre as crianças como um "irrompimento vertical" de bárbaros (ver Meillasoux, 1994) - ou seja, sua (não intitulada?) intrusão ou sua (hostil?) invasão. 2. Referências a Parsons e Davis são feitas em parte porque eles são sociólogos e em parte porque seus trabalhos - deliberadamente e conscientemente concluíram e argumentaram a favor - foram indicativos de nossa percepção cultural sobre a posição das crianças, ou seja, em espera. Inúmeras expressões em linguagem coloquial e em documentos políticos (ver James, 2008) apresentam as crianças meramente em relação ao seu futuro - como por exemplo "as crianças são a próxima geração", "as crianças são 0 futuro", e assim por diante.

3. A expressão que encontramos atualmente, de acordo com o pensamento sociológico tradicional, que as crianças são percebidas "não como seres humanos, mas como futuros humanos" foi originalmente formulada durante esse período (Qvotrup, 1985, p. 132). 
a nossa fase enquanto crianças. Isso está de acordo também com as discussões dominantes sobre mobilidade individual, as quais, por sua vez, coincidem com o sistema de valores da nossa sociedade. Pensar em termos estruturais rompe com os planos de vida pessoal; faz pensar não em termos do desenvolvimento da criança, mas, particularmente, no desenvolvimento da infância.

Em termos estruturais, a infância não tem um começo e um fim temporais, e não pode, portanto, ser compreendida de maneira periódica. É compreendida, mais apropriadamente, como uma categoria permanente de qualquer estrutura geracional. As duas noções de infância - enquanto um período e enquanto uma categoria permanente - não se contradizem. Elas podem e, de fato, coexistem lado a lado, mas os significados de ambas são bem diferentes, conforme exemplificado na Figura 1.

Figura 1: Modelo de relações geracionais.

\begin{tabular}{|l|l|l|l|}
\hline & Infância & Idade adulta & Velhice \\
\hline 2000 & & & \\
\hline 1980 & & & \\
\hline 1960 & & & \\
\hline 1940 & & & \\
\hline 1920 & & & \\
\hline
\end{tabular}

Fonte: elaborada pelo autor.

Este artigo não detalha diversas abordagens antecipatórias. Pode ser pedagogicamente útil, no entanto, colocá-las resumidamente lado a lado utilizando a abordagem sociológica para destacar as características mais importantes da infância enquanto categoria estrutural.

A Figura 1 tem o propósito de demonstrar a infância tanto como um período quanto uma categoria estrutural permanentes. A primeira coluna mostra em cada célula a cronologia histórica em termos de distância entre as categorias geracionais - estabelecida aqui em 20 anos.

A primeira linha representa as três categorias geracionais ou escalão etário ${ }^{4}$.

\section{A infância enquanto período: o} desenvolvimento da criança

Na Figura 1 existem duas setas que se referem à infância enquanto período; devemos nos concentrar na seta apontada para cima ${ }^{5}$, a qual representa um indivíduo e uma orientação antecipatória. Nesse exemplo a seta crescente tem seu início na década de 1980 e seu fim na década atual. É um período de aproximadamente 20 anos, correspondente ao período da infância de uma pessoa. A criança nasceu em 1982, por exemplo, e, portanto - se sobreviver -, alcançará a idade adulta em $2000^{6}$. 0 período ou a fase de vida individuais da criança representa dessa forma a transição para a idade adulta.

Curiosamente, estamos aqui utilizando uma terminologia característica para descrever essa transição pessoal. A dinâmica do desenvolvimento infantil ocorre por meio de mudanças significativas nas disposições do indivíduo, que conhecemos por meio dos diversos modelos de desenvolvimento infantil: da imaturidade (por exemplo, sexual) à maturidade, da incompetência (por exemplo, cognitiva) à competência, da incapacidade (por exemplo, motora funcional) à capacidade, e assim por diante.

Uma vez que essas e a maioria das outras mudanças descritas pela psicologia evolucionária são invariavelmente vistas como movimentos de um estado menos desejável para um mais desejável; elas parecem coincidir com antecipações de aperfeiçoamento estipuladas de forma normativa conforme a criança realiza a sua transição para a fase da vida adulta.

4. Obviamente, a extensão do período da infância tem se transformado ao longo da história (ver p. ex., Gillis, 1974, p. 2, 104 e 208) e é de qualquer modo discutível. Podemos também acrescentar mais categorias geracionais, como, por exemplo, a juventude. No entanto, o que é importante observar é o princípio que rege as relações.

5. A seta decrescente pode convenientemente ser chamada de psiquiátrica, ou seta psicanalítica, no sentido de que um adulto pode ser analisado por meio de reflexão sobre os eventos e experiências da infância para que se possa, com isso, interpretar a situação adulta e/ou possivelmente curar seus problemas. A chave para compreendermos, por exemplo, a psicopatologia em adultos reside na infância, da mesma forma que a chave para entender o futuro das crianças quando adultas reside na infância atual.

6.0s dezoito anos normalmente marcam o fim do perído da infância, e correspondem, também, à definição estabelecida pela Convenção dos Direitos da Criança, da ONU. 
A sua orientação antecipatória é demonstrada por meio da ênfase na socialização e nos métodos de educação que tem o seu objetivo na idade adulta, ou, para colocar de maneira diferente, com o propósito de superar a infância com sucesso. Em alguns países, as autoridades falam explicitamente sobre a Outcomes-Based Education (OBE), isto é, "Educação Baseada em Resultados”, onde são incluídas nos resultados qualidades como a de ser um bom trabalhador, esposo ou esposa, pai, mãe, cidadão etc. ${ }^{7}$.

Nesse sentido, a expressão é reveladora quando nos deparamos com frases típicas como, por exemplo, o nosso objetivo de integrar a criança na sociedade com sucesso. A frase sugere, talvez até inconscientemente, que a criança não é um membro da sociedade, em outras palavras, que sociedade é exatamente a mesma coisa que sociedade adulta. É obviamente certo afırmar que uma criança não é um adulto integrado na sociedade, o que não parece, contudo, que isso seja condição necessária para ser completo enquanto indivíduo. As crianças são dessa forma, por definição, excluídas da sociedade, uma vez que a sua integração a esta marca o fato da sua infância ter chegado ao fim ${ }^{8}$.

Não fosse por esse discurso dominante, isso poderia ter passado despercebido. Como é de praxe nas ciências dominantes no estudo da criança, como a Psicologia, a Pediatria e a Pedagogia - mas também em linguagem coloquial e pelas próprias crianças - a perspectiva ilustrada por meio da seta crescente na Figura 1 é antecipatória, no plano individual, e descreve a transição de um periodo para outro na vida de uma pessoa.

\section{A infância enquanto categoria permanente: o desenvolvimento da infância}

Os representantes dos estudos sociais sobre a infância parecem concordar que a terminologia de antecipação da fase da vida adulta não é muito útil. Uma série de estudiosos tem feito declarações, às vezes na forma de teses, sobre a natureza da infância em termos estruturais. Por essa razão, a infância é "um componente estrutural e cultural específico de muitas sociedades" (Prout; James, 1990, p. 8), "um componente das estruturas da sociedade" - não uma fase preparatória” (Mayall, 1996, p. 58), "inserido no contexto do desenvolvimento social” (Zeiher, 1996, p. 37), "um padrão cultural nas mudanças históricas das relações geracionais” (Honig; Leu; Nissen, 1996, p. 21) e outros autores poderiam ser mencionados (Alanen, 1992; Qvortrup, 1993; James; Jenks; Prout, 1998; Sgritta, 2002; Corsaro, 2005). Ao mesmo tempo encontramos com frequência um uso da terminologia que está longe de ser consistente, oscilando entre o entendimento individual e estrutural da infância, e desatentamente utilizando os termos criança e infância de maneira permutável.

Assim, para se chegar a uma compreensão sociológica, as dimensões verticais e horizontais da Figura 1 são necessárias. Cada uma das células da figura representa uma categoria estrutural - em qualquer fase - da infância, idade adulta ou velhice ${ }^{9}$. Cada célula é definida por um conjunto de parâmetros sociais ou estruturais. É fácil nomear tais parâmetros, mas é difícil ser completo: estamos falando de parâmetros econômicos, políticos, sociais, culturais e tecnológicos, e certamente temos em mente também parâmetros ideológicos e/ou discursivos, ou seja, parâmetros que representam os entendimentos e ideologias sobre crianças e infância. É a interação entre os parâmetros ${ }^{10}$ que produz todas as configurações sociais, incluindo

7. A princípio, a OBE e outras orientações antecipatórias justificam qualquer método que conduza ao resultado desejado, uma vez que o objetivo mais importante é alcançar a idade adulta.

8. Se todos os indivíduos "não integrados" para aquele propósito são crianças é uma outra questão, não menos interessante; dessa forma, adultos que pendem, por exemplo, para a insanidade, fraqueza de espírito ou abuso de drogas estão judicialmente desprovidos da sua maioridade, tornando-se, conquentemente, menores do ponto de vista legal, ou seja, retornaram à posição da infância.

9. Obviamente, outras categorias como a juventude e a meia-idade também têm sido representadas, mas a quantidade não é importante para 0 argumento em questão.

10. Não é preciso dizer que, no final do dia, esses parâmetros são artificiais de acordo com o famoso ditado de Marx extraído da Ideologia Alemã: "0 homem pode fazer a sua História, mas não pode fazer nas condições por ele escolhidas". É outra questão decidir se as crianças devem ser incluídas na noção de "homem"! 
os grupos sociais e as relações entre eles. Em qualquer fase, portanto, a infância é o resultado de fortes relações entre os parâmetros prevalecentes, os quais devem ser todos considerados como forças estruturais.

A Figura 1 nos traz a oportunidade de discutir - ao longo da dimensão vertical - o desenvolvimento da infância, e - ao longo da dimensão horizontal - a infância enquanto categoria geracional.

A categoria estrutural da infância na França dos anos 1920 - para fazer uma alusão mais palpável - foi o resultado da interação entre parâmetros, os quais assumem certos valores nessa época e lugar. Nas décadas de 1940, 1960 e mais adiante, a infância enquanto categoria estrutural foi transformando-se conforme a modificação dos valores e as relações entre os parâmetros. Nesse sentido, a infância, enquanto espaço social no qual as crianças vivem, transforma-se constantemente, da mesma forma que a idade adulta e a velhice também se modificam. Essas transformações não podem esconder, no entanto, a contínua existência e realidade da infância enquanto categoria estrutural. Em termos estruturais, portanto, ela não é transitória e não é um período; tem permanência. $O$ desenvolvimento histórico da infância não acaba com a sua categoria; e a variabilidade cultural da infância contemporânea testemunha a favor da sua presença universal.

Em outras palavras, a infância tanto se transforma de maneira constante assim como é uma categoria estrutural permanente pela qual todas as crianças passam. A infância existe enquanto um espaço social para receber qualquer criança nascida e para incluí-la - para o que der e vier por todo o período da sua infância. Quando essa criança crescer e se tornar um adulto, a sua infância terá chegado ao fim, mas enquanto categoria a infância não desaparece, ao contrário, continua a existir para receber novas gerações de crianças. Hardman descreveu dessa forma em um primeiro artigo de 1973, depois reimpresso: "As crianças entram e saem dessa categoria, mas outras ocupam o seu lugar. A categoria continua a existir” (p. 504).
Na Figura 1 isso pode ser visto no movimento duplo: de um período histórico a outro (de 1920 a 1940 a 1960 etc.) a infância continua a existir, ainda que sujeita a transformações; ao mesmo tempo, também notamos - se acompanharmos a seta crescente - que todos os períodos individuais da infância desaparecem por completo ${ }^{11}$.

A perspectiva vertical - histórica - ilustra dessa forma, podemos dizer, o desenvolvimento da infância (ao invés do desenvolvimento da criança). Essa noção, o desenvolvimento da infância, propõe um entendimento de infância que é completamente diferente do seu equivalente individual. É uma noção cuja dinâmica se encontra nos parâmetros sociais, e não nas características individuais.

Imagine que nos peçam para visualizar a infância na França de cem anos atrás. Uma vez que é impossível apreender todos os períodos da infância das crianças francesas, iremos provavelmente visualizar aquilo que representa a característica central da infância francesa utilizando o nosso conhecimento histórico acerca dos valores e das interações entre os parâmetros mais comuns que levaram à criação do modelo estrutural da infância francesa no início do século XX. Era uma infância - comparada à situação atual - caracterizada pela presença de mais irmãos e irmãs, mortalidade infantil elevada, dramática escassez de tecnologia (ausência de carros, Tecnologia da Informação, quase nenhum cinema, pouquíssimos aparelhos de telefone), baixo padrão de educação, precariedade na saúde, maior número de crianças trabalhando, baixa taxa de divórcios, e assim por diante. Muitos desses parâmetros também exerceram impacto sobre outros grupos etários, de forma que, em termos gerais, todas as categorias geracionais estão a princípio expostas aos mesmos parâmetros externos, ainda que o impacto sofrido por elas seja de intensidade e força diferentes.

11. É possível dessa forma combinar infância e infâncias - ou seja, tanto a forma plural quanto a singular. Todos os períodos individuais da infância desaparecem, mas a infância enquanto categoria estrutural permanece. 
Obviamente, a infância individual de cada criança francesa dentro de qualquer período histórico da infância supõe manifestações únicas, mas fundamentalmente não se desvia e não pode desviar-se dela. Mesmo que todos concordem que a infância francesa há um século não era uniforme, a maioria de nós iria provavelmente também concordar que seus parâmetros assumiriam valores bem diferentes daqueles que vigem atualmente na infância francesa - o que as torna bastante distintas.

Quando argumentamos que a infância se modifica ao longo da história ao mesmo tempo que permanece enquanto categoria, estamos afırmando que existe mudança e continuidade. Os parâmetros da infância têm seus valores alterados constantemente (do ponto de vista interno, no entanto, em ritmos e velocidades diversos ${ }^{12}$ ). Contudo, a infância mantém certos padrões que a tornam passivel de contraste, porque sofre o impacto basicamente dos mesmos conjuntos de parâmetros. Mesmo no decurso de distantes intervalos históricos e culturais, a infância deve ser reconhecível e identificável contanto que faça sentido empregar esse conceito.

Se, por um lado, a infância enquanto período é uma fase transitória para que cada criança se torne um adulto, por outro, enquanto categoria estrutural, a infância não pode nunca se transformar em algo diferente e menos ainda em idade adulta. No entanto, é absolutamente significativo falar sobre a transição de infância de um período histórico para outro ${ }^{13}$.

\section{A infância enquanto categoria permanente: a infância enquanto categoria geracional}

Agora, se analisarmos a dimensão horizontal da Figura 1, estamos nos propondo a pensar em termos de estrutura geracional. Comparada à seta, em que cada criança se relaciona à sua idade adulta por meio da transição "em que se tornam integradas à sociedade", conforme pudemos notar, a infância no nível horizontal está integrada à estrutura geracional em qualquer período da história. Em seguida, entendemos essa estrutura transversalmente, enquanto uma coexistência de categorias geracionais contemporâneas. Desse modo, não faz sentido afırmar que a infância não é parte integrante da sociedade; ao contrário, não seria possível imaginar existirmos sem a infância, assim como a idade adulta e a velhice devem existir enquanto categorias geracionais.

Foi sugerido acima que todas as categorias geracionais estão sujeitas, a principio, aos mesmos parâmetros - sejam eles econômicos, tecnológicos, culturais, e assim por diante. É sensato acrescentar, no entanto, que as categorias geracionais não sofrem ou lidam com o impacto desses parâmetros da mesma maneira. Elas estão em posições diferentes na ordem social. Meios, recursos, influência e poder estão distribuídos de maneira diferente entre as categorias, cujas habilidades para enfrentar os desafios externos consequentemente variam. Por último, as categorias podem discutivelmente ter interesses especiais, o que levanta a questão de como os interesses são satisfeitos, promovidos e/ou evitados, ou seja, a questão de o que é, em termos gerais, chamado de conflito de gerações e como ele é abordado ou solucionado.

As relações entre gerações não assumem necessariamente a forma de conflitos ou divisões; elas podem simplesmente ser consideradas como diferenças ou, na realidade, como interesses em comum.

0 ponto importante é que a perspectiva geracional é indispensável para chegar a um consenso sobre a natureza da relação.

Pode ser útil fazer uma breve comparação dessa categoria a outras categorias estruturais como, por exemplo, uma classe social ou um grupo de gênero. Uma vez que esses grupos ou categorias estruturais são, todos eles, construções sociais, no sentido de que foram criados por inúmeros parâmetros, eles são comparáveis

12. Ou seja, os valores referentes ao parâmetro econômico não mudam exatamente na mesma velocidade que os valores, por exemplo, tecnológicos, culturais ou os parâmetros sociais, os quais, por outro lado, têm ritmo diferente do parâmetro discursivo, por exemplo.

13. A pergunta reside em saber se devemos falar sobre infância ou infâncias. 
às categorias estruturais em termos geracionais. A permanência da categoria em questão significa que a sua existência não depende de constituintes específicos, mesmo que, é claro, esses constituintes possam exercer influência sobre elas. Uma classe social não depende, em termos de mobilidade individual, da entrada ou saída de uma ou outra pessoa. Um grupo de gênero, da mesma forma, continuará a existir à medida que existam diferenças sociais entre os mundos feminino e masculino; ele não desaparece simplesmente porque alguém morre ou deixa o grupo de gênero.

Classes sociais e gêneros de grupos têm permanência, assim como as categorias geracionais também têm. Todos eles estão sujeitos, ao mesmo tempo, a mudanças devido às alterações dos parâmetros sociais e, talvez, também às mudanças de tamanho e composição do grupo.

A principal particularidade a respeito das categorias estruturais, em termos de gerações, - se comparadas àquelas em termos de classe e gênero - é a relativamente rápida rotação de seus constituintes: no que diz respeito à infância, podemos dizer que ela experiencia 100\% de mobilidade em direção à idade adulta - ou, se preferir, uma substituição sempre total de geração (independentemente de como é defınida: atualmente a cada 18 anos). A princípio, esta não é diferente de outras categorias geracionais (idade adulta, velhice) ou mesmo de grupos de gênero. Aqui, as substituições também acontecem automaticamente, mesmo que levem um tempo maior - lembrando outra vez que isso depende das circunstâncias históricas e sociais. Classes sociais não preveem um automatismo similar na substituição de seus constituintes, embora estendam a sua existência além dos membros individuais.

\section{Aplicações de uma perspectiva estrutural}

Alguém pode, é claro, questionar a necessidade ou importância de introduzir uma perspectiva estrutural na infância. A resposta imediata é que perseguimos essa tarefa porque esperamos criar percepções que não serão produzidas por outras perspectivas, incluindo abordagens arraigadas que estudam a criança e sua etapa de vida. É preciso ter-se em mente que, enquanto categoria estrutural, a infância é separada da criança como indivíduo, e, por conseguinte o método para adquirir percepções, tanto históricas quanto geracionais, acerca da infância não demanda necessariamente que as crianças sejam diretamente observadas ou questionadas. 0 que estamos buscando é o universo das crianças ou a estrutura em que elas vivem suas vidas. No final, é obviamente de máxima importância distinguir como os parâmetros exercem influência sobre as crianças - tanto as mais próximas quanto as mais distantes. No entanto, da mesma maneira, sabemos bem que muitos parâmetros, talvez os que mais influenciam a vida das crianças, são definidos sem sequer levar em consideração as crianças e a infância.

É importante que façamos novamente uma analogia entre classe e gênero. Como sabemos, um discernimento essencial é adquirido acerca das classes sociais "por elas mesmas", ou seja, sobre as suas supostas circunstâncias externas, sem que necessariamente saibamos algo específico sobre seus trabalhadores e proletários. Podemos, da mesma forma, obter um conhecimento valioso sobre a relação entre homens e mulheres a partir de um estudo histórico de seu desenvolvimento na sociedade - lembrando, mais uma vez, que isso é possivel sem que se necessite ter conhecimento sobre algum homem ou mulher em específico.

Portanto, ao compreender a definição acima, a qual propõe a infância como categoria estrutural, teremos de levar em consideração e entender amplamente os parâmetros que descrevem e explicam as circunstâncias da vida das crianças para que, dessa forma possamos chegar a uma conclusão a esse respeito.

A partir de um contexto histórico, o qual denominamos desenvolvimento da infância, devemos acompanhar a princípio as mudanças da totalidade de parâmetros e suas próprias interações. 
Isso é o que fez - talvez de modo impreciso e incompleto - o historiador Philippe Ariès (1982) quando acompanhou o desenvolvimento da infância em uma época em que isso, supostamente, não fazia parte da consciência das pessoas por meio

de um longo processo de segregação [...] que tem persistido até os nossos dias, e o qual é chamado de isolamento da educação escolar da criança e sua passagem para a racionalidade... (p. 7)

Podemos falar sobre a institucionalização da infância e, mais especificamente, sobre a escolarização da infância como sendo um resultado das demandas provenientes de uma economia e de um sistema de governo em transformação. Esses desenvolvimentos mudaram dramaticamente a discussão sobre a vida das crianças. Embora houvesse agentes que se esforçaram arduamente para promover a educação escolar das crianças, nos perguntamos se isso teria acontecido caso esta não tivesse sido entendida como um interesse indispensável para o comércio, para o desenvolvimento da indústria e da sociedade de forma geral, e assim por diante.

Quando a antropóloga Ruth Benedict sugeriu em seu famoso artigo que "de um ponto de vista comparativo, a nossa cultura atinge extremos incriveis ao enfatizar os contrastes entre a criança e o adulto", e comentou que "todos esses são dogmas da nossa cultura, os quais, apesar dos fatos relacionados à sua natureza, outras culturas geralmente não compartilham" (Benedict, 1938), o seu foco não era nem a socialização e nem a criança como tal. Eram observações, mais propriamente, sobre $a$ posição geracional da infância, que foram recolhidas a partir da análise de várias culturas durante o primeiro terço do século XX. O mesmo aconteceu com a sua colega Margaret Mead (1972), que, inspirando-se também em experiências obtidas a partir de culturas coexistentes, observou relações diferentes entre gerações. Ela fez distinção entre três culturas diferentes a pós-figurativa, na qual a crianças aprendem primeiramente com os mais velhos, a co-figurativa, em que as crianças e os adultos aprendem com seus semelhantes, e a pré-figurativa, em que os adultos também aprendem com seus filhos. (p. 31)

0 que Benedict e Mead percebem como diferenças a partir de suas evidências contemporâneas também pode ser avaliado como mudanças em comparações históricas das culturas e sociedades. As principais perguntas são, no entanto, por que essas diferenças existem, qual é a sua natureza, e por que as relações geracionais se transformam ao longo da história.

As respostas para essas questões, do ponto de vista sociológico, não podem ser encontradas nas alterações de comportamentos individuais ou no preparo psicológico ${ }^{14}$, mas, principalmente, nas transformações da cultura e da sociedade. As pessoas reagem às novas configurações das condições econômicas, sociais e tecnológicas; e as categorias sociais envolvem-se em determinadas situações novas de contribuição mútua tanto no nível social quanto local e familiar.

Isso pode ser difícil de avaliar no que diz respeito às crianças, porque não estamos acostumados a compreendê-las em termos estruturais. A princípio, a situação é comparável às áreas que nos são mais familiares. Não nos resta dúvida, por exemplo, de que as relações entre homens e mulheres têm transformado-se ao longo do tempo (e que culturas contemporâneas apresentam diferenças de gênero). Essas transformações dificilmente aconteceram devido a mudanças inerentes às mulheres e/ou aos homens, mas, ao invés disso, porque os papéis dos gêneros mudam como resultado de alterações sociais. As mulheres receberam educação, e, consequentemente, juntaram-se aos homens no mercado de trabalho. As relações de gênero assumiram formas e conteú-

14. DeMause se aproxima de tal interpretação com sua teoria psicogenética da história (DeMause, 1975, p. 3). Sua rejeição à função da tecnologia e da economia em benefício das mudanças de personalidade reduz a credibilidade da sua teoria entre os cientistas sociais. 
dos novos em conjunto com as transformações estruturais - isso tudo facilitado pela ação das mulheres (e talvez de alguns homens também, que em várias circunstâncias consideraram que isso também fosse do seu interesse).

Parece ser fácil avaliar transformações em situações tão familiares quanto as que se referem ao coletivo dos adultos. Existiram mudanças semelhantes entre as gerações? Conforme foi proposto por Benedict e Mead, as crianças assumem diferentes posicionamentos em comparação aos adultos em culturas ou sociedades distintas. Nada é alterado, naturalmente, no fato de que toda criança está caminhando em direção à idade adulta; contudo, o que difere são as condições e as circunstâncias em que isso acontece. Isto é, em outras palavras, a infância, em termos estruturais, assume formas diferentes como resultado das transformações sociais.

Os exemplos de Ariès, Benedict e Mead ilustram de certa forma um desenvolvimento histórico e, até certo ponto, variações interculturais na estrutura em que as crianças vivem. Essas mudanças e variações aconteceram principalmente devido às demandas na economia e no sistema de governo. Elas não são menos reais por conta disso, e está a cargo dos pesquisadores da infância desvendar novos contextos de importância significativa para a vida das crianças.

Um exemplo interessante e importante a respeito das mudanças nas relações intergeracionais pode ser extraído dos desenvolvimentos demográficos, ou seja, desenvolvimentos em que as crianças não podem ser causadoras, mas que, contudo, provocaram impacto sobre elas. Primeiramente, uma pirâmide populacional nos ajuda a visualizar como a infância tem ocupado cada vez menos espaço ao longo do tempo; por essa razão, a sua categoria estrutural está quase literalmente minimizada. Os fatores responsáveis por isso, ou, talvez por melhor dizer, de acordo com essas mudanças demográficas, são todos os que, em outras circunstâncias, influenciarão a infância, como, por exemplo, crescimento econômico, industrialização, urbanização, aumento na qualidade da saúde, secularização, individualização, educação, privatização da família, e outros. Como resultado, a infância tem tornado-se menor - tanto em nível familiar quanto social. A atitude tem tornado-se mais sentimentalista, mais protetora, pelo menos em nível familiar. 0 sociólogo James Coleman tem utilizado as estatísticas dos EUA para mostrar como as crianças são afetadas em termos relativos de desenvolvimento. Devido a alterações demográficas, a parcela de famílias sem crianças teve um aumento de 27\% em 1870 para 64\% em 1983. No mesmo período, a renda per capita das crianças em relação aos adultos diminuiu de 71\% para 51\% (Coleman, 1990).

Esse exemplo mostra como os desenvolvimentos estruturais impactam a infância de maneira diferente, quer seja em nível familiar ou social. Podemos argumentar que as relações entre as crianças e seus pais têm tornado-se mais próximas, afetivas e protetoras, enquanto que em nível social elas têm sido entendidas em termos de negligência ou indiferença estrutural, para usar a frase do sociólogo alemão Kaufmann (2005) ${ }^{15}$. Quando observamos os números de Coleman, fica fácil notar que a diminuição da renda das crianças em relação a todos os adultos resulta do fato de que cada vez menos adultos, ou seja, menos pais, estão assumindo responsabilidade por crianças. Mesmo que (ainda) seja verdade que a maioria dos adultos seja ou venha a ser pai ou mãe, é ao mesmo tempo certo que as crianças correm um risco maior de possuir renda menor ou viver em estado de pobreza em comparação aos adultos enquanto coletivo. Quanto menor a taxa de natalidade, maior é a possibilidade de esse cenário ser verdadeiro. Em outros tempos, como sugerem os números de Coleman, tanto os recursos como as responsabilidades eram mais igualmente estendidos aos dois, vida e comunidade.

Os exemplos da influência dos parâmetros estruturais sobre a infância e as crianças são enormes. Eles não sugerem que são superiores a

15. A língua alemã permite que se faça uma distinção prática entre a qualidade das relações: em nível familiar Beziehungen e em nível social Verhältnisse (cf. Klassenverhältnisse) (ver Honig, 1999). 
outros métodos para se chegar a uma compreensão, mas devem ser percebidos como um método adicional para entender como a infância se desenvolve e como as crianças, enquanto categoria social ou grupo, se saem, quando comparadas a outras categorias geracionais.

Não é necessariamente o caso de afirmar que o desenvolvimento ocorre de forma negativa para as crianças e a infância. Primeiramente, o propósito não é, em hipótese alguma, fazer esse tipo de pergunta. A questão principal é descobrir o impacto dessas macrovariáveis na infância.

Nos últimos anos, principalmente nas duas últimas décadas, temos visto um crescimento extraordinário em tecnologia de computadores. Margaret Mead não sabia disso, ainda que em seu livro mencionado acima esse desenvolvimento já estivesse em formação e pudesse ser previsto. Se seguirmos sua linha de raciocínio, tudo indica que as crianças terão vantagens comparativas significativas sobre os mais velhos na sociedade, e principalmente a geração mais velha pode ficar em desvantagem no domínio dessa nova tecnologia. Ao mesmo tempo, a geração mais velha está tornando-se cada vez mais numerosa, e dessa forma vem adquirindo, em princípio, cada vez mais poder político. É difícil dizer no que esse desenvolvimento vai resultar tanto no nível social quanto familiar.

A verdade é que o estudo das inter-relações entre gerações enquanto categorias estruturais será indispensável para que possamos prever e possivelmente melhorar o futuro $d a$ infância. Para que possamos lidar com o futuro da infância precisamos pensar de maneira criativa sobre a futura configuração dos parâmetros já bem conhecidos, e em particular as mudanças nos valores desses parâmetros. Mais uma vez, isso é completamente diferente de prever o futuro não menos importante da criança.

\section{Referências bibliográficas}

ALANEN, L. Modern childhood? Exploring the "Child Question" in Sociology. Jyväskylä: University of Jyväskylä, 1992.

AMBERT, A.-M. Sociology of sociology: the place of children in North American sociology. Sociological Studies of Child Development, v. 1, p. 11-31, 1986.

ARIĖS, P. Barndommens historie. Copenhagen: NNF Arnold Busck, 1982. (Edição dinamarquesa resumida de L'Enfant et la vie familiale sous l'ancien regime, 1960, com o prefácio do autor publicado na nova edição francesa de 1973.)

BENEDICT, R. Continuities and discontinuities in cultural conditioning. Psychiatry, v. 1, n. 2, p. 161-67, 1938.

COLEMAN, J. S. Foundations of social theory. Cambridge/London: Harvard Univesity Press, 1990.

CORSARO, W. A. The sociology of childhood. Thousands Oaks: Pine Forge Press, 2005.

DAVIS, K. The child and the social structure. The Journal of Educational Sociology, v. 14, n. 4, p. 217-29, 1940.

DeMAUSE, L. The evolution of childhood. In:___. The history of childhood. New York: The Psychohistory Press, 1975. p. 1-73.

FÜRSTENAU, P. Soziologie der Kindheit. Heidelberg: Quelle \& Meyer, 1973.

GILLIS, J. R. Youth and history: tradition and change in European Age Relations - 1770-present. New York/London: Academic Press, 1974.

HARDMAN, C. (1973). Can there be an anthropology of children? Childhood, v. 8, n. 4, p. 501-17, 2001.

HONIG, M.-S. Entwurf einer Theorie der Kindheit. Frankfurt: Suhrkamp, 1999. 
HONIG, M.-S.; LEU, H. R.; NISSEN, U. Kindheit als Sozialisationsphase und als kulturelles Muster. In: soziokulturelle Muster - sozialisationstheoretische Perspektiven. Weinheim/München: Juventa, 1996. p. 9-29.

Kinder und Kindheit

JAMES, A. Changing childhood in the UK: reconstructing discourses of "risk" and "protection". In: European childhoods: cultures, politics and childhoods in Europe. Basingstoke: Palgrave Macmillan, 2008. p. 105-128.

JAMES, A.; JENKS, C.; PROUT, A. Theorizing childhood. Cambridge: Polity Press, 1998.

KAUFMANN, F.-X. Schrumpfende Gesellschaft: Vom Bevölkerungsrückgang und seine Folgen. Frankfurt: Suhrkamp, 2005.

MAYALL, B. Children, health and the social order. Buckingham: Open University Press, 1996.

MEAD, M. Culture and commitment: a study of the Generation Gap. Herts: Panter Books, 1972.

MEILLASSOUX, C. Kapitalistische Produktion von “Über-bevölkerung” in Afrika. Das Argument 204, v. 36, n. 2, p. 219-232, 1994.

PARSONS, T. The social system. London: Free Press, 1964.

PROUT, A.; JAMES, A. A new paradigm for the sociology of childhood? Provenance, promise and problems. In: Constructing and reconstructing childhood. London: Falmer Press, 1990. p. 7-34.

QVORTRUP, J. Placing children in the division of labour. In: CLOSE, P.; COLLINS, R. (Eds.). Family and economy in modern society Basingstoke/London: Macmillan, 1985. p. 129-145.

Nine theses about "childhood as a social phenomenon". In: Childhood as a social phenomenon: lessons from an international project. Vienna: European Centre, 1993. p. 11-18. (Eurosocial Report 47.)

From useful to useful: the historical continuity of children's constructive participation. Sociological Studies of Children, v. 7, p. 49-76, 1995.

SGRITTA, G. B. Inconsistencies: childhood on the economic and political agenda. In: MOURITSEN, F.; QVORTRUP, J. (Eds.). Childhood and children's culture. Odense: Odense University Press, 2002. p. 209-260.

THORNE, B. Re-visioning women and social change: where are the children? Gender and Society, v. 1, n. 1, p. 85-109, 1987.

ZEIHER, H. Kinder in der Gesellschaft und Kindheit in der Soziologie. Zeitschrift für Sozialisationssforschung und Erziehungssoziologie, v. 16, n. 1, p. 26-46, 1996.

Jens Qvortrup é professor do Departamento de Sociologia e Ciência Política - Norwegian University for Science and Technology (NTNU), Trondheim, Noruega. 